\title{
Oral NAloxone to overcome the moRphine effect in acute COronary syndrome patients treated with TICagrelor - NARCOTIC trial
}

\author{
Piotr Niezgoda $^{1 *}$, Malwina A. Barańska ${ }^{1 *}$, Joanna Sikora ${ }^{2}$, \\ Przemysław Sobczak ${ }^{2}$, Katarzyna Buszko ${ }^{3}$, Adam Sikora ${ }^{4}$, \\ Michał P. Marszałł ${ }^{4}$, Eliano P. Navarese ${ }^{1,5,6}$, Bernd Jilma ${ }^{7}$, Jacek Kubica ${ }^{1}$ \\ ${ }^{1}$ Department of Cardiology and Internal Medicine, Collegium Medicum, \\ Nicolaus Copernicus University, Bydgoszcz, Poland \\ ${ }^{2}$ Department of Pharmacology and Therapy, Collegium Medicum, \\ Nicolaus Copernicus University, Bydgoszcz, Poland \\ ${ }^{3}$ Department of Theoretical Foundations of Biomedical Science and Medical Informatics, \\ Collegium Medicum, Nicolaus Copernicus University, Bydgoszcz, Poland \\ ${ }^{4}$ Department of Medicinal Chemistry, Collegium Medicum, \\ Nicolaus Copernicus University, Bydgoszcz, Poland \\ ${ }^{5}$ Interventional Cardiology and Cardiovascular Medicine Research, Mater Dei Hospital, Bari, Italy \\ ${ }^{6}$ Mazankowski Alberta Heart Institute, University of Alberta, Edmonton, Alberta, Canada \\ ${ }^{7}$ Department of Clinical Pharmacology, Medical University of Vienna, Austria
}

\begin{abstract}
Background: Numerous worldwide clinical trials have proven the indisputably negative influence of morphine on the pharmacokinetics and pharmacodynamics of $P 2 Y_{12}$ receptor inhibitors in patients presenting with acute coronary syndromes. The aim of this trial was to evaluate whether oral coadministration of an anti-opioid agent, naloxone, can be considered a successful approach to overcome 'the morphine effect'.

Methods: Consecutive unstable angina patients receiving ticagrelor and morphine with or without orally administered naloxone underwent assessment of platelet reactivity using Multiplate analyzer as well as evaluation of the pharmacokinetic profile of ticagrelor and its active metabolite, AR-C124910XX, at 9 pre-defined time points within the first 6 hours following oral intake of the ticagrelor loading dose. Results: The trial shows no significant differences regarding the pharmacokinetics of ticagrelor between both study arms throughout the study period. AR-C124910XX plasma concentration was significantly higher $120 \mathrm{~min}$ after the ticagrelor loading dose administration $(p=0.0417)$. However, the evaluation of pharmacodynamics did not show any statistically significant differences between the study arms.

Conclusions: To conclude, this trial shows that naloxone co-administration in ticagrelor-treated acute coronary syndrome patients on concomitant treatment with morphine shows no definite superiority in terms of ticagrelor pharmacokinetic and pharmacodynamic profile. (Cardiol J 2022; 29, 3: 432-440)

Key words: acute coronary syndrome, unstable angina, ticagrelor, morphine, naloxone
\end{abstract}

Address for correspondence: Piotr Niezgoda, MD, Department of Cardiology and Internal Medicine, Collegium Medicum, Nicolaus Copernicus University, ul. Skłodowskiej 9, 85-094 Bydgoszcz, Poland, tel: +48 5258540 23,

e-mail: piotr.niezgoda1986@gmail.com

Received: 24.09.2019 Accepted: 25.02.2020 Early publication date: 18.03.2020

*Equal contributors.

This article is available in open access under Creative Common Attribution-Non-Commercial-No Derivatives 4.0 International (CC BY-NC-ND 4.0) license, allowing to download articles and share them with others as long as they credit the authors and the publisher, but without permission to change them in any way or use them commercially. 


\section{Introduction}

The development of contemporary treatment of acute coronary syndromes (ACS) has forced the establishment of methods of rapid platelet inhibition. The results of the PLATO trial proved the superiority of ticagrelor over well-known and widely used clopidogrel in terms of its effectiveness, mainly demonstrated by the reduction of the composite endpoint including cardiovascular death, myocardial infarction or stroke with no significant increase of the risk of clinically significant bleeding [1]. Based on those findings ticagrelor has become the treatment of choice in patients presenting with ACS according to currently available guidelines [2-6].

Numerous ACS patients, especially those presenting with ST-segment elevation myocardial infarction (STEMI), require strong and effective analgesia. The most commonly used analgesic medication nowadays is morphine [2]. Morphine administration used to be considered beneficial for ACS patients as it was thought to be associated not only with pain alleviation, but also with a positive tranquilizing effect on treated individuals. Several international studies however, have revealed a negative interaction between morphine and $\mathrm{P} 2 \mathrm{Y}_{12}$ receptor inhibitors leading to decrease of the plasma concentrations of those platelet inhibitors and their metabolites as well as delay and attenuation of their antiplatelet activity [7-11]. The discovery of the negative influence of morphine on the pharmacokinetic/pharmacodynamics (PK/PD) profile of ticagrelor in ACS patients resulted in a decrease of class of recommendation for morphine use to class IIa for STEMI based on the latest guidelines [2]. Morphine has been found to negatively influence gastric emptying, impair intestinal motility, reduce intestinal secretion and induce nausea or vomiting [12]. The phenomenon presented above can be called 'the morphine effect'.

Naloxone, a selective opioid receptor antagonist, is widely used to diminish negative effects of opioid drugs. Its utility is most pronounced in opioid substitution therapy in cases of opioid addiction or reversal of opioid action in opioid intoxication. Typically, in such clinical situations, naloxone is administered parenterally. However, if administered orally, it has been proven to successfully reduce the negative impact on gastrointestinal tract by relieving opioid-related constipation in oncological patients requiring regular opioid administration. This approach allows the elimination of intestinal motility impairment without risking attenuation of the analgesic activity of an opioid, as naloxone administered orally is associated with a strong first-pass effect making its serum concentration barely detectable. The final bioavailability of the drug after oral administration ranges from $2 \%$ to $3 \%$ [13-16].

On the basis of the aforementioned findings it was hypothesized that co-administration of naloxone may prove beneficial as a potential method of overcoming 'the morphine effect' in ACS patients treated with ticagrelor who received morphine.

\section{Methods}

\section{Study design and population}

A pharmacokinetic/pharmacodynamic, phase IV, single center, investigator-initiated, randomized, open-label, active-controlled trial was designed and it was conducted in accordance with Good Clinical Practice and the Declaration of Helsinki guidelines. The previously published study protocol [17] was approved by The Ethics Committee of The Nicolaus Copernicus University in Torun, Collegium Medicum in Bydgoszcz (approval number KB 540/2015). Any study-related procedures were undertaken only after obtainment of informed consent to participate in the trial from each study participant. Males and non-pregnant females, aged 18-80 years, admitted to the Department of Cardiology, A. Jurasz University Hospital in Bydgoszcz, Poland due to unstable angina and qualified for coronary angiography, underwent eligibility screening. The complete list of inclusion and exclusion criteria is presented in Table 1.

Patients admitted to the Department of Cardiology, due to unstable angina received orally a $300 \mathrm{mg}$ loading dose (LD) of plain acetylsalicylic acid (Polpharma SA, Starogard Gdanski, Poland) and underwent eligibility screening for participation in the study. Having consented to participate in the trial, eligible patients were randomized in a 1:1 ratio into two study arms as follows - the active study arm including patients receiving: 1) crushed tablets of $180 \mathrm{mg}$ ticagrelor in $10 \mathrm{~mL}$ suspension in tap water administered orally; 2) $5 \mathrm{mg}$ of morphine administered intravenously; 3 ) $1 \mathrm{mg}$ of naloxone administered orally; and the control group treated with: 1) crushed tablets of $180 \mathrm{mg}$ ticagrelor in $10 \mathrm{~mL}$ suspension in tap water administered orally; and 2) $5 \mathrm{mg}$ of morphine administered intravenously. The Random Allocation Software version 1.0. was used for the process of randomization.

Based on the results of studies previously conducted in the present department, oral ad- 
Table 1. A complete list of inclusion/exclusion criteria for the study.

\begin{tabular}{|c|}
\hline Inclusion criteria (all criteria must be met) \\
\hline Provision of informed consent prior to any study specific procedures \\
\hline Diagnosis of unstable angina \\
\hline Male or non-pregnant female, aged $18-80$ years \\
\hline Provision of informed consent for angiography and percutaneous coronary intervention \\
\hline GRACE score $<140$ patients \\
\hline Exclusion criteria (none of the criteria can be met) \\
\hline Treatment with ticlopidine, clopidogrel, prasugrel or ticagrelor within 14 days before study enrollment \\
\hline Current treatment with morphine or any opioid "mi" receptor agonist \\
\hline Hypersensitivity to ticagrelor \\
\hline Current treatment with oral anticoagulant or chronic therapy with low-molecular-weight heparin \\
\hline Active bleeding \\
\hline History of intracranial hemorrhage \\
\hline Recent gastrointestinal bleeding (within 30 days) \\
\hline History of coagulation disorders \\
\hline Platelet count less than $100 \times 10^{3} / \mathrm{mcl}$ \\
\hline Hemoglobin concentration less than $10.0 \mathrm{~g} / \mathrm{dL}$ \\
\hline History of moderate or severe hepatic impairment \\
\hline History of major surgery or severe trauma (within 3 months) \\
\hline Risk of bradycardic events as judged by the investigator \\
\hline Second- or third-degree atrioventricular block during screening for eligibility \\
\hline History of asthma or severe chronic obstructive pulmonary disease \\
\hline Kidney disease requiring dialysis \\
\hline Manifest infection or inflammatory state \\
\hline Killip class III or IV during screening for eligibility \\
\hline Respiratory failure \\
\hline History of severe chronic heart failure (NYHA class III or IV) \\
\hline $\begin{array}{l}\text { Concomitant therapy with strong CYP3A inhibitors (ketoconazole, itraconazole, voriconazole, telithromycin, } \\
\text { clarithromycin, nefazadone, ritonavir, saquinavir, nelfinavir, indinavir, atazanavir) or strong CYP3A inducers } \\
\text { (rifampicin, phenytoin, carbamazepine, dexamethasone, phenobarbital) within } 14 \text { days and during study treatment }\end{array}$ \\
\hline Body weight below $50 \mathrm{~kg}$ \\
\hline
\end{tabular}

ministration of crushed ticagrelor was chosen as it was associated with the optimal pharmacokinetic and pharmacodynamic profile in unstable angina patients [18]. Only patients with low and intermediate risk of in-hospital mortality as assessed with the GRACE scale were enrolled in the study, which allowed completion of the whole blood sampling schedule before coronary angiography, avoiding the risk of its unpredictable impact on platelet function. Taking into account that morphine negatively affects the absorption of ticagrelor from the gastrointestinal tract, we assumed that addition of an opioid antagonist, naloxone administered orally, would contribute to the optimization of the $\mathrm{PK} / \mathrm{PD}$ profile of tica- grelor and its active metabolite. As assessed in previous studies, a group of 15 patients for each study arm was considered to be sufficient for statistical analysis.

\section{Blood sample collection}

According to the study protocol, following obtainment of informed consent for participation in the study and randomization into the study arms, collection of blood samples for the pharmacokinetic and pharmacodynamic assessment was done. Nine predefined time points of blood sampling were as follows: before the administration of ticagrelor $\mathrm{LD}$ and $15 \mathrm{~min}, 30 \mathrm{~min}, 45 \mathrm{~min}, 1 \mathrm{~h}, 2 \mathrm{~h}, 3 \mathrm{~h}, 4 \mathrm{~h}, 6 \mathrm{~h}$ after its administration. 
Table 2. Complete list of study outcomes.

\begin{tabular}{l} 
Study primary outcome \\
\hline Time to maximum concentration $\left(t_{\max }\right)$ for ticagrelor and AR-C124900XX \\
\hline Study secondary outcomes \\
\hline Maximum ticagrelor and AR-C124900XX concentration \\
Area under the plasma concentration-time curve for ticagrelor (AUC 0-6 h) \\
Area under the plasma concentration-time curve for AR-C124900XX (AUC 0-6 h) \\
Platelet reactivity assessed by multiple electrode aggregometry
\end{tabular}

\section{Pharmacokinetics}

Pharmacokinetic assessment was performed for each study participant at all predefined time points. Plasma concentrations of ticagrelor and its active metabolite were evaluated in The Department of Medicinal Chemistry, Collegium Medicum, Nicolaus Copernicus University, Bydgoszcz using liquid chromatography and mass spectrometry. Measurements were performed using Shimadzu UPLC Nexera X2 system and Shimadzu 8030 ESI-Triple Quadrupole mass spectrometer. The limits of quantification for ticagrelor and its active metabolite were defined as $4.69 \mathrm{ng} / \mathrm{mL}$.

\section{Pharmacodynamics}

The evaluation of pharmacodynamics was performed using the Multiplate analyzer (ADPtest, Roche Diagnostics, Switzerland). The measurements of platelet reactivity were conducted with multiple electrode aggregometry (MEA) at all time points as mentioned above. Area under the aggregation curve (AUC) as a parameter reflecting the overall exposure to both ticagrelor and AR-C124900XX, was assessed on the assumption that AUC > 46 units (U) was defined as high platelet reactivity (HPR).

\section{Study outcomes}

According to the protocol, the primary endpoint of this $\mathrm{PK} / \mathrm{PD}$ study was the time required to reach the maximum plasma concentration of ticagrelor and AR-C124900XX following ticagrelor loading dose intake. Secondary endpoints included maximum concentration of ticagrelor and its metabolite, area under the plasma concentration-time curve $\left(\mathrm{AUC}_{\mathrm{CT}}\right)$ for ticagrelor and $\mathrm{AR}-\mathrm{C} 124900 \mathrm{XX}$ and platelet reactivity assessed by MEA in the aforementioned time points. The complete list of study outcomes is presented in Table 2 .

\section{Statistical analysis}

Statistical analysis was performed using Matlab R2014 Software (Mathworks, Natick, MA,
USA), the Statistica 12.5 package (StatSoft, Tulsa, OK, USA) and R version 3.5.0 (R: library lme). $\mathrm{P}<0.05$ were considered statistically significant. AUC was calculated using the trapezoidal rule. Comparative analysis of pharmacokinetic parameters between the study arms and time points were conducted using mixed models with random effects with the maximum likelihood method applied for estimating variance parameters. Comparison of pharmacodynamic parameters between the study arms was performed with the Fisher exact test.

\section{Results}

\section{Population baseline characteristics}

Between October 2016 and December 2018, a total of 30 unstable angina (UA) patients were enrolled in the study. Baseline serum troponin evaluation required ruling out an acute myocardial infarction was performed for each study participant showing no case of elevation above the reference level of $34.5 \mathrm{ng} / \mathrm{L}$ and $15.6 \mathrm{ng} / \mathrm{L}$ for men and women, respectively. The study population was generally well balanced, except for the prevalence of prior coronary artery disease and consequently prior percutaneous coronary intervention, which were noticeably higher in the study arm $(66.7 \%$ vs. $28.6 \%, \mathrm{p}=0.04$ and $53.3 \%$ vs. $14.3 \%, \mathrm{p}=0.03$, respectively). The study population baseline characteristics are presented in Table 3.

\section{Safety and tolerability evaluation}

The safety evaluation did not reveal any case of serious adverse events such as death, myocardial infarction, stent thrombosis, stroke or thromboembolic events throughout the study. Minor symptoms including weakness and headache were reported by 2 patients in the active arm. On the other hand, adverse effects in the control group of participants included mild bradycardia (50-55 bpm), nausea (2 patients) and excessive sweating associated with feeling unwell (1 patient). Due to 
Table 3. Study population baseline characteristics.

\begin{tabular}{|c|c|c|c|}
\hline & Study group $(\%)(n=15)$ & Control group $(\%)(n=14)$ & $\mathbf{P}$ \\
\hline Age [years] & $66.87^{*}$ & $60.21 *$ & 0.56 \\
\hline Male & $12(80)$ & $7(50)$ & 0.089 \\
\hline Body weight [kg] & $88.73^{*}$ & $77.48^{*}$ & 0.25 \\
\hline Body mass index $\left[\mathrm{kg} / \mathrm{m}^{2}\right]$ & $29.05^{*}$ & $27.24^{*}$ & 0.89 \\
\hline Prior CAD & $10(66.7)$ & $4(28.6)$ & 0.04 \\
\hline Prior AMI & $8(53.3)$ & $3(21.4)$ & 0.08 \\
\hline Prior PCl & $8(53.3)$ & $2(14.3)$ & 0.03 \\
\hline Prior CABG & $3(20.0)$ & $3(21.4)$ & 0.95 \\
\hline Arterial hypertension & $12(80.0)$ & $9(64.3)$ & 0.34 \\
\hline Prior peptic ulcer disease & $3(20.0)$ & $1(7.1)$ & 0.31 \\
\hline Prior gastrointestinal bleeding & $1(6.7)$ & $1(7.1)$ & 0.96 \\
\hline Prior stroke/TIA & $2(13.3)$ & $1(7.1)$ & 0.59 \\
\hline CKD & 0 & $1(7.1)$ & 0.29 \\
\hline Hyperlipidemia & $13(86.7)$ & $12(85.7)$ & 0.94 \\
\hline Current smoker & $1(6.7)$ & $3(21.4)$ & 0.23 \\
\hline History of smoking & $8(53.3)$ & $4(28.6)$ & 0.18 \\
\hline Family history of CAD & $5(33.3)$ & $9(64.3)$ & 0.09 \\
\hline Diabetes mellitus & $3(20.0)$ & $4(28.6)$ & 0.59 \\
\hline Insulin therapy & 0 & $3(21.4)$ & 0.06 \\
\hline COPD & 0 & $1(7.1)$ & 0.30 \\
\hline Peripheral atherosclerosis & $3(20.0)$ & $2(14.3)$ & 0.68 \\
\hline
\end{tabular}

*Data are shown as mean. AMI - acute myocardial infarction; CABG — coronary artery bypass grafting; CKD — chronic kidney disease;

COPD - chronic obstructive pulmonary disease; CAD — coronary artery disease; $\mathrm{PCl}$ — percutaneous coronary intervention; TIA — transient ischemic attack

vomiting that required immediate administration of metoclopramide, a prokinetic drug, 1 patient's participation in the trial was terminated, which resulted in exclusion of the initially obtained results of pharmacokinetics and pharmacodynamics of this participant from statistical analysis.

\section{Pharmacokinetics}

Pharmacokinetic assessment was performed for each study participant. Statistical analysis of all results showed only a trend toward a better PK profile in the naloxone arm. Mixed models with random effects showed no significant differences between the study arms in terms of ticagrelor-related parameters. However, the difference between plasma concentrations of AR-C124910XX obtained at $120 \mathrm{~min}$ following ticagrelor $\mathrm{LD}$ reached statistical significance $(p=0.0417)$. PK parameters obtained throughout the study are presented in Table 4. Mean concentration of ticagrelor and its active metabolite is presented in Figures 1 and 2 .

\section{Pharmacodynamics}

The PD evaluation was performed for each patient, revealing no significant differences between the study arms. The superiority of the naloxone arm in terms of percentage of HPR patients at particular time points patients was only numerical. The most pronounced difference was observed at $30 \mathrm{~min}$ following ticagrelor LD (7 vs. 10 patients) for the naloxone and control arm respectively ( $\mathrm{p}=0.18$; Fig. 3$)$.

\section{Discussion}

The recent discovery of the so-called 'morphine effect' brought new challenges into contemporary ACS treatment strategies. As mentioned before, co-administration of morphine in the course of ACS is no longer a first-line approach due to its negative impact on $\mathrm{P} 2 \mathrm{Y}_{12}$ receptor inhibitors $\mathrm{PK} /$ /PD profile. Inevitably, some patients, especially presenting with STEMI, will require strong anal- 
Table 4. Pharmacokinetic parameters of ticagrelor and AR-C124910XX in mixed model with random effects.

\begin{tabular}{|c|c|c|c|}
\hline & Value & Standard error & P-value \\
\hline \multicolumn{4}{|l|}{ Ticagrelor } \\
\hline Intercept & -274.1965 & 184.04303 & 0.1377 \\
\hline Time 15 vs. time 0 & 14.0322 & 223.66104 & 0.9500 \\
\hline Time 30 vs. time 0 & 145.4685 & 223.66104 & 0.5161 \\
\hline Time 45 vs. time 0 & 451.1968 & 223.66104 & 0.0449 \\
\hline Time 60 vs. time 0 & 762.1987 & 223.66104 & 0.0008 \\
\hline Time 120 vs. time 0 & 694.5401 & 223.66104 & 0.0022 \\
\hline Time 180 vs. time 0 & 880.6841 & 223.66104 & 0.0001 \\
\hline Time 240 vs. time 0 & 832.2042 & 223.66104 & 0.0003 \\
\hline Time 360 vs. time 0 & 589.4043 & 223.66104 & 0.0090 \\
\hline Group I vs. group II & 79.2077 & 45.08410 & 0.0803 \\
\hline Time 15 group & 5.8586 & 58.01639 & 0.9197 \\
\hline Time 30 group & 30.3315 & 58.01639 & 0.6016 \\
\hline Time 45 group & 40.3730 & 58.01639 & 0.4872 \\
\hline Time 60 group & 31.6464 & 58.01639 & 0.5860 \\
\hline Time 120 group & 82.9364 & 58.01639 & 0.1543 \\
\hline Time 180 group & -7.0878 & 58.01639 & 0.9029 \\
\hline Time 240 group & -4.6060 & 58.01639 & 0.9368 \\
\hline Time 360 group & 24.9611 & 58.01639 & 0.6674 \\
\hline \multicolumn{4}{|l|}{ Metabolite } \\
\hline Intercept & -48.18294 & 39.93862 & 0.2290 \\
\hline Time 15 vs. time 0 & 0.00000 & 49.98636 & 1.0000 \\
\hline Time 30 vs. time 0 & -3.58612 & 49.98636 & 0.9429 \\
\hline Time 45 vs. time 0 & 17.25228 & 49.98636 & 0.7303 \\
\hline Time 60 vs. time 0 & 66.51414 & 49.98636 & 0.1847 \\
\hline Time 120 vs. time 0 & 160.11218 & 49.98636 & 0.0016 \\
\hline Time 180 vs. time 0 & 229.63223 & 49.98636 & 0.0000 \\
\hline Time 240 vs. time 0 & 258.55988 & 49.98636 & 0.0000 \\
\hline Time 360 vs. time 0 & 177.13110 & 49.98636 & 0.0005 \\
\hline Group I vs. group II & 13.79099 & 9.97219 & 0.1681 \\
\hline Time 15 group & 0.00000 & 12.96617 & 1.0000 \\
\hline Time 30 group & 4.96449 & 12.96617 & 0.7022 \\
\hline Time 45 group & 14.83565 & 12.96617 & 0.2538 \\
\hline Time 60 group & 19.00707 & 12.96617 & 0.1441 \\
\hline Time 120 group & 26.55748 & 12.96617 & 0.0417 \\
\hline Time 180 group & 6.51674 & 12.96617 & 0.6158 \\
\hline Time 240 group & -4.16173 & 12.96617 & 0.7485 \\
\hline Time 360 group & 8.45659 & 12.96617 & 0.5150 \\
\hline
\end{tabular}

gesic agents to relieve unbearable pain associated with the infarction. Until now, several approaches to reduce 'the morphine effect' have been described in the literature.

The present study is the first one aiming to assess the influence of oral naloxone on ticagrelor and
AR-C124900XX in ACS patients who received morphine. The results show no definite benefit in terms of the PK and PD profile of ticagrelor in the naloxone arm, however a trend toward improvement of analyzed parameters could be observed. 


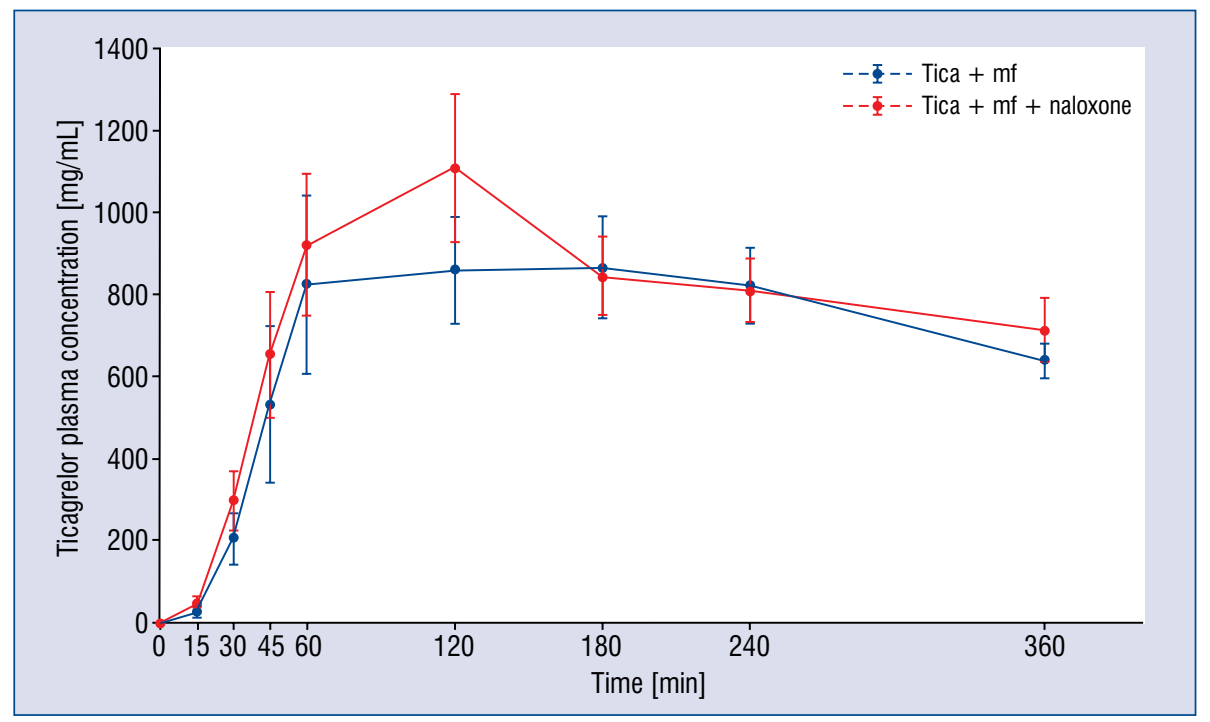

Figure 1. Mean ticagrelor plasma concentration throughout the study; tica — ticagrelor; mf — morphine.

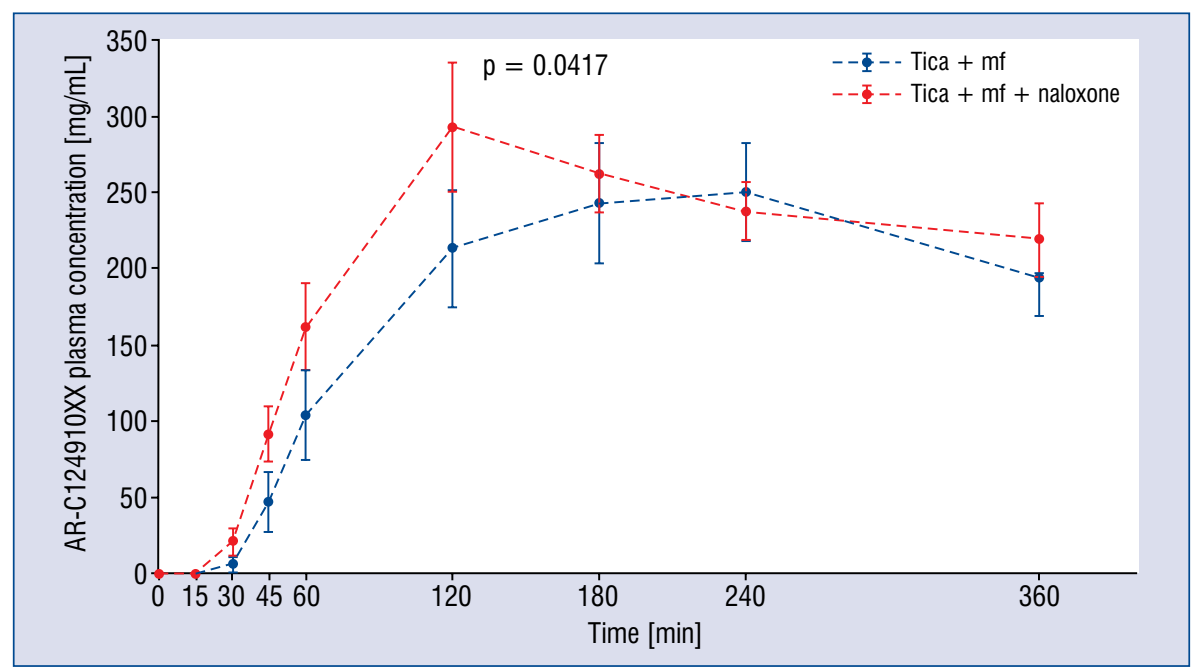

Figure 2. Mean concentration of the active metabolite, AR-C124910XX throughout the study; tica - ticagrelor; $\mathrm{mf}$ - morphine.

In our previous study it was proved that coadministration of an anti-emetic agent, metoclopramide, leads to higher plasma concentrations of ticagrelor and its active metabolite and reduction of time required to reach maximum plasma concentrations of ticagrelor and its metabolite (123 min vs. 168 min for control arm, $p=0.015$ ) [19].

The PK/PD profile of currently used $\mathrm{P}_{2} \mathrm{Y}_{12}$ receptor inhibitors has also been found to be noticeably dependent on the administration strategy of the drug. No inconsistencies can be found in terms of the administration of crushed tablets of $\mathrm{P}^{2} \mathrm{Y}_{12}$ inhibitors. Zafar et al. [20] proved that the administration of clopidogrel in healthy volunteers was associated with faster and greater bioavailability if the drug was given as a crushed form via a nasogastric tube. According to a study by Rollini et al. [21], administration of crushed prasugrel in STEMI patients led to faster absorption of this agent. Also, it was associated with higher plasma concentrations of its metabolite and reduction of platelet reactivity $30 \mathrm{~min}$ after the $\mathrm{LD}$ of prasugrel. 


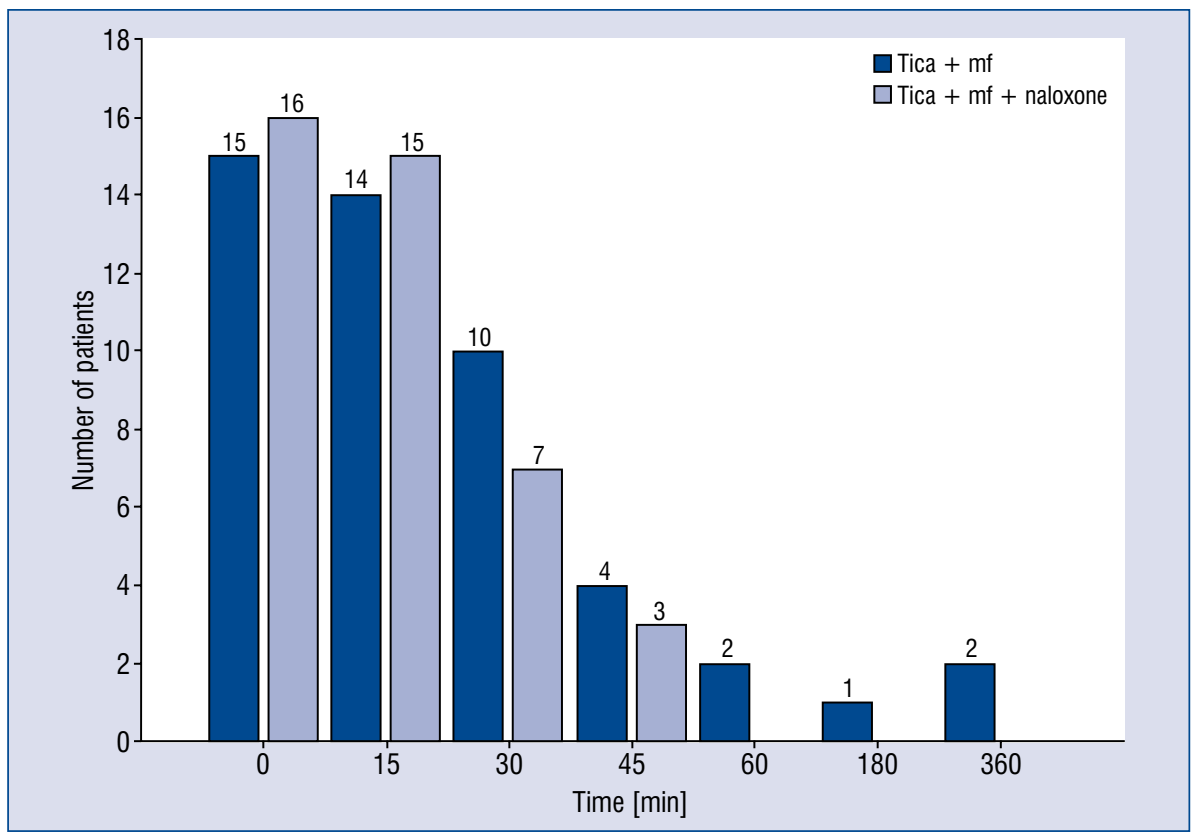

Figure 3. Proportion of patients with high platelet reactivity in study time points.

In the MOHITO study, Parodi et al. [22] reported that the time required to achieve platelet inhibition in STEMI patients was significantly shorter if they received crushed ticagrelor instead of standard integral tablets. Oral administration of crushed ticagrelor was also associated with the best PK/ /PD profile of ticagrelor and its active metabolite in our previous study evaluating the influence of ticagrelor administration strategy in patients presenting with UA. Moreover, the above-mentioned study demonstrated this strategy to be superior over sublingual administration of crushed ticagrelor [18].

The results of the latest studies aiming to evaluate the impact of ticagrelor administration strategy on its $\mathrm{PK} / \mathrm{PD}$ profile show superiority of chewed ticagrelor in terms of platelet reactivity units (PRU) measured with VerifyNow in nonSTEMI patients at $1 \mathrm{~h}$ where it was found to be significantly lower [23]. In a study by Venetsanos et al. [24] PRU were also significantly lower in patients presenting with stable angina pectoris in the chewed-ticagrelor arm in comparison with integral ticagrelor arm.

\section{Limitations of the study}

The study population comprised only UA patients, thus baseline platelet reactivity does not fully reflect characteristics of STEMI patients.
A limited number of study participants might have negatively influenced the statistical analysis as only a trend toward improvement of the PK profile could be observed in the naloxone arm. Although the prevalence of prior coronary artery disease in the naloxone group was higher than in the control group, it did not affect baseline platelet reactivity.

\section{Conclusions}

According to available research, this study is the first one to evaluate the impact of an anti-opioid drug, naloxone, on PK and PD of ticagrelor and its active metabolite. Even though a trend toward improvement of the PK/PD profile of ticagrelor in ACS patients pre-treated with morphine followed by oral naloxone is perceptible, further research is required to determine optimal approaches to overcome the 'morphine effect'.

Conflict of interest: Malwina Barańska received honoraria for lectures from AstraZeneca. Bernd Jilma has served as a consultant to and in advisory boards of AstraZeneca. Jacek Kubica delivered a lecture for AstraZeneca. All of the other authors declare no potential conflict of interests regarding publication of this paper. 


\section{References}

1. Cannon C, Harrington R, James S, et al. Comparison of ticagrelor with clopidogrel in patients with a planned invasive strategy for acute coronary syndromes (PLATO): a randomised doubleblind study. The Lancet. 2010; 375(9711): 283-293, doi: 10.1016/ s0140-6736(09)62191-7.

2. Ibanez B, James S, Agewall S, et al. ESC Scientific Document Group. 2017 ESC Guidelines for the management of acute myocardial infarction in patients presenting with ST-segment elevation: The Task Force for the management of acute myocardial infarction in patients presenting with ST-segment elevation of the European Society of Cardiology (ESC). Eur Heart J. 2018; 39(2): 119-177, doi: 10.1093/eurheartj/ehx393, indexed in Pubmed: 28886621 .

3. Roffi M, Patrono C, Collet JP, et al. ESC Scientific Document Group . 2015 ESC Guidelines for the management of acute coronary syndromes in patients presenting without persistent ST-segment elevation: Task Force for the Management of Acute Coronary Syndromes in Patients Presenting without Persistent ST-Segment Elevation of the European Society of Cardiology (ESC). Eur Heart J. 2016; 37(3): 267-315, doi: 10.1093/eurheartj/ ehv320, indexed in Pubmed: 26320110.

4. Jneid H, Anderson JL, Wright RS, et al. 2012 ACCF/AHA focused update of the guideline for the management of patients with unstable angina/Non-ST-elevation myocardial infarction (updating the 2007 guideline and replacing the 2011 focused update): a report of the American College of Cardiology Foundation/American Heart Association Task Force on Practice Guidelines. J Am Coll Cardiol. 2012; 60: 645-81.

5. O'Gara PT, Kushner FG, Ascheim DD, et al. American College of Cardiology Foundation, American Heart Association Task Force on Practice Guidelines, American College of Emergency Physicians, Society for Cardiovascular Angiography and Interventions. $2013 \mathrm{ACCF} / \mathrm{AHA}$ guideline for the management of ST-elevation myocardial infarction: executive summary: a report of the American College of Cardiology Foundation/American Heart Association Task Force on Practice Guidelines: developed in collaboration with the American College of Emergency Physicians and Society for Cardiovascular Angiography and Interventions. Catheter Cardiovasc Interv. 2013; 82(1): E1-27, doi: 10.1002/ccd.24776, indexed in Pubmed: 23299937.

6. Kubica J, Adamski P, Paciorek P, et al. Treatment of patients with acute coronary syndrome: Recommendations for medical emergency teams: Focus on antiplatelet therapies. Updated experts' standpoint. Cardiol J. 2018; 25(3): 291-300, doi: 10.5603/ CJ.a2018.0042, indexed in Pubmed: 29671864.

7. Meine TJ, Roe MT, Chen AY, et al. CRUSADE Investigators. Association of intravenous morphine use and outcomes in acute coronary syndromes: results from the CRUSADE Quality Improvement Initiative. Am Heart J. 2005; 149(6): 1043-1049, doi: 10.1016/j.ahj.2005.02.010, indexed in Pubmed: 15976786

8. Kubica J, Adamski P, Ostrowska M, et al. Morphine delays and attenuates ticagrelor exposure and action in patients with myocardial infarction: the randomized, double-blind, placebo-controlled IMPRESSION trial. Eur Heart J. 2016; 37(3): 245-252, doi: 10.1093/eurheartj/ehv547.

9. Parodi G, Bellandi B, Xanthopoulou I, et al. Morphine is associated with a delayed activity of oral antiplatelet agents in patients with ST-elevation acute myocardial infarction undergoing primary percutaneous coronary intervention. Circ Cardiovasc Interv. 2015; 8(1), doi: 10.1161/CIRCINTERVENTIONS.114.001593, indexed in Pubmed: 25552565.

10. Hobl EL, Stimpfl T, Ebner J, et al. Morphine decreases clopidogrel concentrations and effects: a randomized, double-blind, placebo-controlled trial. J Am Coll Cardiol. 2014; 63(7): 630-635, doi: 10.1016/j.jacc.2013.10.068, indexed in Pubmed: 24315907.
11. Hobl EL, Reiter B, Schoergenhofer C, et al. Morphine decreases ticagrelor concentrations but not its antiplatelet effects: a randomized trial in healthy volunteers. Eur J Clin Invest. 2015; 46(1): 7-14, doi: 10.1111/eci.12550.

12. Kubica J, Kubica A, Jilma B, et al. Impact of morphine on antiplatelet effects of oral P2Y12 receptor inhibitors. Int J Cardiol. 2016; 215: 201-208, doi: 10.1016/j.ijcard.2016.04.077, indexed in Pubmed: 27128531.

13. Greenwood-Van Meerveld B, Gardner CJ, Little PJ, et al. Preclinical studies of opioids and opioid antagonists on gastrointestinal function. Neurogastroenterol Motil. 2004; 16 Suppl 2: 46-53, doi: 10.1111/j.1743-3150.2004.00555.x, indexed in Pubmed: 15357851.

14. Smith K, Hopp M, Mundin G, et al. Low absolute bioavailability of oral naloxone in healthy subjects. Int J Clin Pharmacol Ther 2012; 50(5): 360-367, doi: 10.5414/cp201646, indexed in Pubmed: 22541841.

15. Choi YS, Billings JA. Opioid antagonists: a review of their role in palliative care, focusing on use in opioid-related constipation. J Pain Symptom Manage. 2002; 24(1): 71-90, doi: 10.1016/s08853924(02)00424-4, indexed in Pubmed: 12183097.

16. Sykes NP. An investigation of the ability of oral naloxone to correct opioid-related constipation in patients with advanced cancer. Palliat Med. 1996; 10(2): 135-144, doi: 10.1177/026921639601000208, indexed in Pubmed: 8800821.

17. Barańska M, Niezgoda P, Kubica J. The influence of naloxone on pharmacokinetics and pharmacodynamics of ticagrelor in patients with unstable angina pectoris receiving concomitant treatment with morphine - a protocol of a randomized trial. Med Res J. 2018, doi: 10.5603/mrj.a2018.0035.

18. Niezgoda P, Sikora J, Barańska M, et al. Crushed sublingual versus oral ticagrelor administration strategies in patients with unstable angina. A pharmacokinetic/pharmacodynamic study. Thromb Haemost. 2017; 117(4): 718-726, doi: 10.1160/TH1608-0670, indexed in Pubmed: 28203684.

19. Sikora J, Niezgoda P, Barańska M, et al. METoclopramide Administration as a Strategy to Overcome MORPHine-ticagrelOr Interaction in PatientS with Unstable Angina PectorIS - The METAMORPHOSIS Trial. Thromb Haemost. 2018; 118(12): 2126-2133, doi: 10.1055/s-0038-1675605, indexed in Pubmed: 30453344.

20. Zafar MU, Farkouh ME, Fuster V, et al. Crushed clopidogrel administered via nasogastric tube has faster and greater absorption than oral whole tablets. J Interv Cardiol. 2009; 22(4): 385-389, doi: 10.1111/j.1540-8183.2009.00475.x, indexed in Pubmed: 19496900.

21. Rollini F, Franchi F, Angiolillo DJ, et al. Crushed prasugrel tablets in patients with STEMI undergoing primary percutaneous coronary intervention: the CRUSH study. J Am Coll Cardiol. 2016; 67(17): 1994-2004, doi: 10.1016/j.jacc.2016.02.045, indexed in Pubmed: 27012781.

22. Parodi G, Xanthopoulou I, Bellandi B, et al. Ticagrelor crushed tablets administration in STEMI patients: the MOJITO study. J Am Coll Cardiol. 2015; 65(5): 511-512, doi: 10.1016/j. jacc.2014.08.056, indexed in Pubmed: 25660931.

23. Asher E, Frydman S, Katz M, et al. Chewing versus swallowing ticagrelor to accelerate platelet inhibition in acute coronary syndrome - the CHEERS study. For the PLATIS (platelets and thrombosis in sheba) study group. Thromb Haemost. 2017; 117(4): 727-733, doi: 10.1160/TH16-09-0728, indexed in Pubmed: 28150850 .

24. Venetsanos D, Sederholm Lawesson S, Swahn E, et al. Chewed ticagrelor tablets provide faster platelet inhibition compared to integral tablets: The inhibition of platelet aggregation after administration of three different ticagrelor formulations (IPAAD-Tica) study, a randomised controlled trial. Thromb Res. 2017; 149: 88-94, doi: 10.1016/j.thromres.2016.10.013, indexed in Pubmed: 27773347. 